\title{
Scattering Theory of Waves and Particles
}

\author{
Roger G. Newton
}

DOVER PUBLICATIONS, INC.

Mineola, New York 


\section{Contents}

1 Formalism and General Results 3

1.1 The Maxwell Equations 3

1.2 Stokes Parameters and Polarization 4

1.2.1 Definition of the Stokes Parameters 4

1.2.2 Significance of the Parameters 6

1.2.3 Partially Polarized Beams

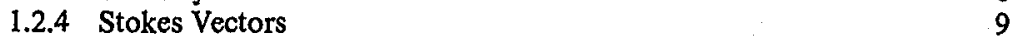

$\begin{array}{ll}1.2 .5 & \text { Relation to the Density Matrix } \\ 10\end{array}$

$\begin{array}{lll}1.3 \text { Scattering } & 11\end{array}$

1.3.1 The Scattering Amplitude 11

1.3.2 Change to a Reference Plane through a Fixed Direction 12

1.3.3 Relation of Circular to Linear Polarization Components in the Scattering Amplitude

1.3.4 Stokes Vectors of the Scattered Wave

$\begin{array}{ll}\text { 1.3.5 The Differential Cross Section } & 14\end{array}$

1.3.6 The Density Matrix of the Scattered Wave 15

1.3.7 Azimuthal Dependence of Forward and Backward Scattering 16

1.3.8 Effects of Rotational or Reflectional Symmetry 16

1.3.9 Forward Scattering; the Optical Theorem 18

$\begin{array}{ll}1.4 \text { Double Scattering } & 20\end{array}$

1.5 Scattering by a Cloud of Many Particles 23

1.5.1 Addition of Cross Sections 23

$\begin{array}{ll}\text { 1.5.2 Index of Refraction } & 24\end{array}$

$\begin{array}{ll}\text { 1.5.3 More than One Kind of Particle } & 26\end{array}$

$\begin{array}{ll}\text { Notes and References } & 27 \\ \end{array}$

$\begin{array}{ll}\text { Problems } & 28\end{array}$ 
2 Spherically Symmetric Scatterers $\quad 30$

2.1 Spherical Harmonics 30

2.1.1 Legendre Polynomials 30

2.1.2 Associated Legendre Functions 31

2.1.3 Spherical Harmonics 31

\begin{tabular}{ll}
2.1 .4 & Vector Spherical Harmonics \\
\hline
\end{tabular}

2.1.5 Transverse and Longitudinal Vector Spherical Harmonics 34

2.1.6 Rotationally Invariant Tensor Functions 35

$\begin{array}{ll}\text { 2.1.7 Complex Conjugation Properties } & 36\end{array}$

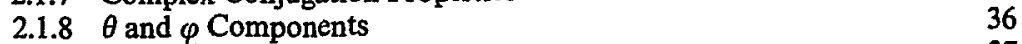

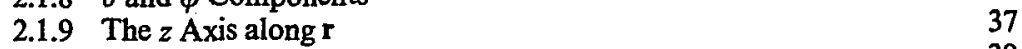

2.2 Multipole Expansions 38

2.2.1 Expansion of a Plane Wave; Spherical Bessel Functions 38

2.2.2 Expansion of the Electric Field $\quad 40$

2.2.3 The Magnetic Field 41

2.2.4 The $\mathscr{K}$ Matrix $\quad 42$

2.2.5 The Scattering Amplitude $\quad 42$

2.2.6 The $z$ Axis along $k \quad 42$

2.3 Unitarity and Reciprocity 44

2.3.1 Energy Conservation and Unitarity 44

2.3.2 Phase Shifts 45

2.3.3 Time Reversal and Reciprocity 46

2.3.4 The Generalized Optical Theorem 47

2.3.5 Generalization to Absence of Spherical Symmetry 48

2.4 Scattering by a Uniform Sphere (Mie Theory) 48

2.4.1 Calculation of the $\mathscr{K}$ Matrix 48

2.4.2 The Scattering Amplitude $\quad 50$

Notes and References 51

Problems

3 Limiting Cases and Approximations 54

3.1 Small Spheres, Not Too Dense (Rayleigh Scattering) 54

3.2 Low Optical Density, Not Too Large (Rayleigh-Gans; Born Approxi- 56 $\begin{array}{ll}\text { mation) } & 56 \\ & 61\end{array}$

$\begin{array}{ll}\text { 3.3 Small Dense Spheres } & 61 \\ 3.31 & 61\end{array}$

$\begin{array}{lll}\text { 3.3.1 } & \text { Resonance Scattering } & 61 \\ \text { 3.3.2 } & \text { Totally Reflecting Spheres } & 65\end{array}$

3.4 Large Diffuse Spheres (Van de Hulst Scattering) 66

3.4.1 Forward Scattering $\quad 66$

3.4.2 Small-Angle Scattering $\quad 69$

3.5 Large Spheres (Geometrical-Optics Limit) 70

3.5.1 Fraunhofer Diffraction $\quad 71$

3.5.2 Nonforward and Nonbackward Scattering; Real Index of 72

$\begin{array}{ll}\text { 3.5.3 Large Diffuse Spheres } & 76\end{array}$

3.5.4 Large Dense Spheres $\quad 77$

3.5.5 Complex Index of Refraction $\quad 77$

3.6 The Rainbow 78

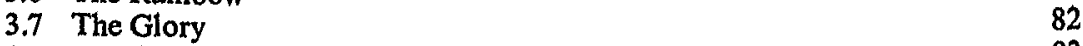

3.8 Grazing Rays (The Watson Method) 83

3.8.1 The Watson Transform $\quad 84$

$\begin{array}{ll}\text { 3.8.2 Convergence Questions } & 90\end{array}$

Appendix: Saddle-Point Integration (The Method of Steepest Descent) 94

Notes and References 96

$\begin{array}{ll}\text { Problems } & 96\end{array}$ 
4 Miscellaneous $\quad 98$

4.1 Other Methods 98

4.1.1 Debye Potentials 98

4.1.2 The Green's-Function Method 100

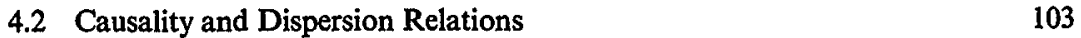

$\begin{array}{ll}\text { 4.2.1 Introduction } & 103\end{array}$

$\begin{array}{ll}\text { 4.2.2 Forward-Dispersion Relations } & 104\end{array}$

$\begin{array}{ll}\text { 4.2.3 Nonforward-Dispersion Relations } & 107\end{array}$

4.2.4 Partial-Wave-Dispersion Relations 109

4.3 Intensity-Fluctuation Correlations (Hanbury Brown and Twiss Effect) $\quad 110$

$\begin{array}{ll}\text { Notes and References } & 116\end{array}$

$\begin{array}{ll}\text { Problems } & 117\end{array}$

$\begin{array}{ll}\text { Additional References for Part I } & 118\end{array}$

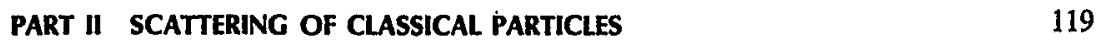

5 Particle Scattering in Classical Mechanics 121

5.1 The Orbit Equation and the Deflection Angle $\quad 121$

$\begin{array}{ll}\text { 5.1.1 The Nonrelativistic Case } & 121\end{array}$

$\begin{array}{ll}\text { 5.1.2 The Relativistic Case } & 123\end{array}$

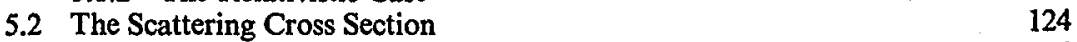

$\begin{array}{ll}\text { 5.3 The Rutherford Cross Section } & 126\end{array}$

$\begin{array}{ll}5.4 \text { Orbiting (Spiral Scattering) } & 127\end{array}$

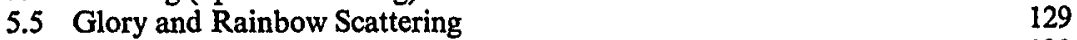

$\begin{array}{ll}\text { 5.6 Singular Potentials } & 130\end{array}$

5.7 Transformation Between Laboratory and Center-of-Mass Coordinate
Systems

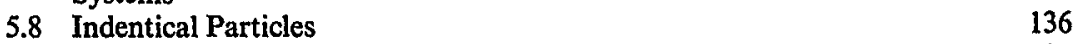

5.9 The Inverse Problem 137

Notes and References 139

$\begin{array}{ll}\text { Problems } & 140\end{array}$

PART III QUANTUM SCATTERING THEORY 141

6 Time-Dependent Formal Scattering Theory 143

6.1 The Schrödinger Equation 145

6.2 Time Development of State Vectors in the Schrödinger Picture : 146

6.3 The M $\phi$ lier Wave Operator in the Schrödinger Picture

$\begin{array}{ll}\text { 6.4 The S Matrix } & 156\end{array}$

6.5 The Interaction Picture 158

6.6 The Heisenberg Picture 160

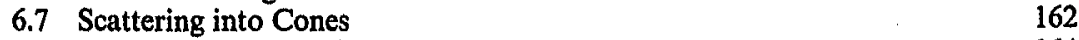

6.8 Mathematical Questions 164

6.8.1 Convergence of Vectors 164

6.8.2 Operator Convergence $\quad 166$

6.8.3 Convergences in the Schrödinger Picture 169

6.8.4 The Limits in the Interaction Picture 171

6.8.5 The Limits in the Heisenberg Picture 172

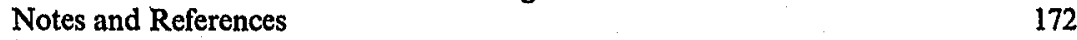

$\begin{array}{ll}\text { Problems } & 174\end{array}$

7 Time-Independent Formal Scattering Theory 175

$\begin{array}{lll}7.1 & \text { Green's Functions and State Vectors } & 176\end{array}$ 
7.1.1 The Green's Functions 176

$\begin{array}{ll}\text { 7.1.2 The State Vectors } & 178\end{array}$

7.1.3 Expansion of the Green's Functions 181

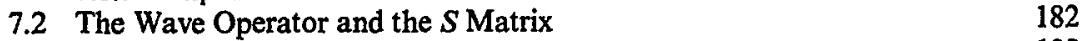

7.2.1 The Operators $\Omega, S$, and $S^{\prime} \quad 182$

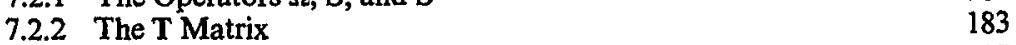

$\begin{array}{ll}\text { 7.2.3 The K Matrix } & 187\end{array}$

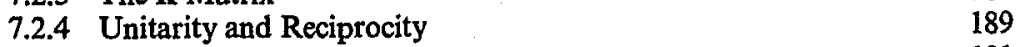

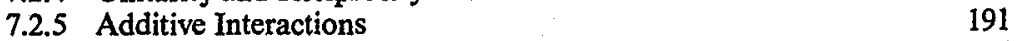

$\begin{array}{ll}\text { 7.3 Mathematical Questions } & 194\end{array}$

$\begin{array}{ll}\text { 7.3.1 The Spectrum } & 195\end{array}$

$\begin{array}{ll}\text { 7.3.2 Compact Operators } & 198\end{array}$

7.3.3 Hermitian and Unitary Operators 200

7.3.4 Analyticity of the Resolvent 204

Appendix

208

$\begin{array}{ll}\text { Notes and References } & 208\end{array}$

$\begin{array}{ll}\text { Problems } & 209\end{array}$

8 Cross Sections 211

8.1 General Definition of Differential Cross Sections $\quad 211$

$\begin{array}{ll}\text { 8.2 Relativistic Generalization } & 215\end{array}$

$\begin{array}{ll}\text { 8.3 Scattering of Incoherent Beams } & 217\end{array}$

$\begin{array}{ll}\text { 8.3.1 The Density Matrix } & 217\end{array}$

$\begin{array}{ll}\text { 8.3.2 Particles with Spin } & 221\end{array}$

8.3.3 The Cross Section and the Density Matrix of the Scattered Wave 225

Notes and References $\quad 226$

$\begin{array}{ll}\text { Problems } & 227\end{array}$

9 Formal Methods of Solution and Approximations 228

$\begin{array}{ll}9.1 \text { Perturbation Theory } & 228\end{array}$

9.1.1 The Born Series 228

9.1.2 The Born Approximation 238

9.1.3 The Distorted-Wave Born Approximation 239

9.1.4 Bound States from the Born Approximation 240

9.2 The Schmidt Process (Quasi Particles) 241

9.3 The Fredholm Method 247

9.4 Singularities of an Operator Inverse 255

$\begin{array}{ll}\text { Notes and References } & 257\end{array}$

$\begin{array}{ll}\text { Problems } & 258\end{array}$

10 Single-Channel Scattering

(Three-Dimensional Analysis in Specific Representations) $\quad 260$

10.1 The Scattering Equation in the One-Particle Case 260

10.1.1 Preliminaries 260

10.1.2 The Coordinate Representation 261

10.1.3 The Momentum Representation 266

10.1.4 Separable Interactions 268

10.2 The Scattering Equations in the Two-Particle Case (Elimination of 270

$\begin{array}{ll}\text { Center-of-Mass Motion) } & 270 \\ & 273\end{array}$

$\begin{array}{lll}\text { 10.3 Three-Dimensional Analysis of Potential Scattering } & 273 \\ \text { 10.3.1 Born Series } & 274\end{array}$

$\begin{array}{ll}\text { 10.3.2 Fredholm Theory } & 277\end{array}$

10.3.3 Scattering Amplitude, Cross Section, and S Matrix 282 
10.3.4 Dispersion Relations $\quad 289$

10.3.5 An Example (the Yukawa Potential) 291

Notes and References $\quad: \quad 295$

$\begin{array}{ll}\text { Problems } & 297\end{array}$

11 Single-Channel Scattering of Spin 0 Particles, I 298

$\begin{array}{lll}11.1 & \text { Partial-Wave Expansion } & 298\end{array}$

11.1.1 The S Matrix and Traveling Waves 298

$\begin{array}{ll}\text { 11.1.2 The } \mathbf{K} \text { Matrix and Standing Waves } & 303\end{array}$

$\begin{array}{ll}\text { 11.1.3 Time Delay } & 304\end{array}$

\begin{tabular}{ll}
11.2 Heuristic Survey of Phase-Shift Behavior 305 \\
\hline
\end{tabular}

$\begin{array}{ll}\text { 11.2.1 General Properties } & 305\end{array}$

11.2.2 Discussion of Low-Energy Phase-Shift Behavior 306

$\begin{array}{ll}11.3 \text { Variational Approaches } & 318\end{array}$

$\begin{array}{lll}\text { 11.3.1 General Introduction } & 318\end{array}$

11.3.2 The T Matrix, K Matrix, and the Green's Function 319

11.3.3 Variational Formulations of the Phase Shift 321

11.3.4 The s-Wave Scattering Length 322

Appendix: Proof of the Hylleraas-Undheim Theorem

$\begin{array}{ll}\text { Notes and References } & 327\end{array}$

$\begin{array}{ll}\text { Problems } & 328\end{array}$

12 Single-Channel Scattering of Spin 0 Particles, II 331

12.1 Rigorous Discussion of $s$-Wave Scattering 331

12.1.1 The Regular and Irregular Solutions 331

12.1.2 The Jost Function and the Complete Green's Function 341

$\begin{array}{lll}12.1 .3 & \text { The S Matrix } & 350\end{array}$

12.1.4 The Poles of $S \quad 357$

12.1.5 Completeness 368

$\begin{array}{ll}12.2 \text { Higher Angular Momenta } & 371\end{array}$

12.3 Continuous Angular Momenta $\quad 380$

$\begin{array}{ll}12.4 & \text { Singular Potentials } \\ & 389\end{array}$

12.4.1 The Difficulties 389

12.4.2 Singular Repulsive Potentials $\quad 392$

12.4.3 An Example $\quad 394$

Notes and References $\quad 396$

General References $\quad 399$

$\begin{array}{ll}\text { Problems } & 399\end{array}$

13 The Watson-Regge Method (Complex Angular Momentum) 402

$\begin{array}{ll}\text { 13.1 The Watson Transform } & 402\end{array}$

13.2 Uniqueness of the Interpolation 408

$\begin{array}{ll}13.3 \text { Regge Poles } & 410\end{array}$

13.4 The Mandelstam Representation $\quad 412$

$\begin{array}{ll}\text { Notes and References } & 415\end{array}$

$\begin{array}{ll}\text { Problems } & 416\end{array}$

14 Examples 417

14.1 The Zero-Range Potential 418

$\begin{array}{ll}\text { 14.2 The Repulsive Core } & 419\end{array}$

14.3 The Exponential Potential $\quad 420$

14.4 The Hulthén Potential 421

14.5 Potentials of the Yukawa Type 422 
14.6 The Coulomb Potential 424

14.6.1 The Pure Coulomb Field 424

14.6.2 Coulomb Admixtures 431

14.7 Bargmann Potentials and Generalizations 433

14.7.1 General Procedure $\quad 433$

14.7.2 Special Cases $\quad 437$

Notes and References $\quad 440$

Problems $\quad 441$

15 Elastic Scattering of Particles with Spin 444

15.1 Partial-Wave Analysis 444

15.1.1 Expansion in $j$ and $s \quad 444$

15.1.2 Amplitudes for Individual Spins 450

15.1.3 Unitarity, Reciprocity, Time-Reversal Invariance, and Parity 452

Conservation $\quad 452$

$\begin{array}{ll}\text { 15.1.4 Special Cases } & 457\end{array}$

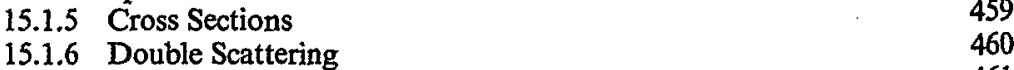

15.1.6 Double Scattering
Solution of the Coupled Schrödinger Equations

15.2 Solution of the Coupled Schrödinger Equations
15.2.1 The Matrix Equation

$\begin{array}{ll}\text { 15.2.2 Solutions } & 462\end{array}$

15.2.3 Jost Matrix and S Matrix 464

15.2.4 Bound States 468

15.2.5 Miscellaneous Remarks 471

$\begin{array}{ll}\text { Notes and References } & 472\end{array}$

$\begin{array}{lr}\text { Problems } & 472\end{array}$

16 Inelastic Scattering and Reactions (Multichannel Theory), I 474

16.1 Descriptive Introduction 474

16.2 Time-Dependent Theory 477

16.2.1 The Schrödinger Picture 477

16.2.2 The Heisenberg Picture 482

16.2.3 Two-Hilbert-Space Formulation 483

16.3 Time-Independent Theory 485

16.3.1 Formal Theory 485

$\begin{array}{ll}\text { 16.3.2 Distorted-Wave Rearrangement Theory } & 487\end{array}$

16.3.3 Identical Particles 488

16.3.4 Large-Distance Behavior of the Two-Cluster Wave Function 489

16.4 Partial-Wave Analysis $\quad 492$

16.4.1 The Coupled Equations $\quad 492$

16.4.2 The S Matrix 494

16.4.3 Rearrangements 495

16.5 General Scattering Rates

16.6 Formal Resonance Theory $\quad 500$

Appendix $\quad 508$

Notes and References $\quad 510$

$\begin{array}{ll}\text { Problems } & 513\end{array}$

17 Inelastic Scaftering and Reactions (Multichannel Theory), II 514

17.1 Analyticity in Many-Channel Problems 514

17.1.1 The Coupled Equations $\quad 514$

17.1.2 An Alternative Procedure $\quad 519$

17.1.3 Analyticity Properties 521 
17.1.4 Bound States $\quad 526$

17.1.5 The Riemann Surface of the Many-Channel S Matrix 528

17.2 Threshold Effects $\quad 534$

17.2.1 Threshold Branch Points 534

17.2.2 Physical Threshold Phenomena; General Arguments 538

17.2.3 Details of the Anomaly $\quad 539$

17.2.4 The Threshold Anomaly for Charged Particles 544

$\begin{array}{lll}17.3 \text { Examples } & 548\end{array}$

$\begin{array}{lll}\text { 17.3.1 The Square Well } & 548\end{array}$

17.3.2 Potentials of Yukawa Type 551

17.3.3 The Wigner-Weisskopf Model $\quad 553$

17.4 The Three-Body Problem 555

17.4.1 Failure of the Multichannel Method and of the Lippmann-
Schwinger Equation

$\begin{array}{ll}\text { 17.4.2 The Faddeev Method } & 558\end{array}$

$\begin{array}{ll}\text { 17.4.3 Other Methods } & 560\end{array}$

17.4.4 Fredholm Properties and Spurious Solutions 563

17.4.5 The Asymptotic Form of Three-Particle Wave Functions 565

17.4.6 Angular Momentum Couplings $\quad 571$

$\begin{array}{ll}\text { 17.4.7 The S Matrix } & 579\end{array}$

17.4.8 The Efimov Effect $\quad 580$

Notes and References $\quad 581$

$\begin{array}{lr}\text { Problems } & 586\end{array}$

18 Short-Wavelength Approximations $\quad 588$

$\begin{array}{ll}18.1 \text { Introduction } & 588\end{array}$

$\begin{array}{ll}\text { 18.1.1 Diffraction from the Optical Theorem } & 590\end{array}$

$\begin{array}{ll}\text { 18.2 The WKB Method } & 591\end{array}$

18.2.1 The WKB Phase Shifts $\quad 591$

18.2.2 The Scattering Amplitude $\quad 594$

$\begin{array}{ll}\text { 18.2.3 The Rainbow } & 597\end{array}$

$\begin{array}{ll}\text { 18.2.4 The Glory } & 598\end{array}$

18.2.5 Orbiting (Spiral Scattering) 600

$\begin{array}{lll}\text { 18.3 The Eikonal Approximation } & 600\end{array}$

18.4 The Impulse Approximation 605

$\begin{array}{ll}\text { Notes and References } & 609\end{array}$

$\begin{array}{ll}\text { Problems } & 611\end{array}$

19 The Decay of Unstable States $\quad 612$

$\begin{array}{lll}19.1 \text { Qualitative Introduction } & 612\end{array}$

19.2 Exponential Decay and Its Limitations 614

19.3 Multiple Poles of the S Matrix $\quad 625$

Notes and References $\quad 626$

$\begin{array}{lr}\text { Problems } & 626\end{array}$

20 The Inverse Scattering Problem 629

$\begin{array}{lll}20.1 \text { Introduction } & 629\end{array}$

20.2 The Phase of the Amplitude 633

20.3 The Central Potential Obtained from a Phase Shift 637

20.3.1 The Gel'fand-Levitan Equations 637

20.3.2 Infinitesimal Variations 645

20.3.3 The Marchenko Equation 648

20.4 The Central Potential Obtained from All Phase Shifts at One Energy 650 
xx Contents

20.4.1 The Construction Procedure 650

20.4.2 Examples 657

20.5 The Inverse Scattering Problem for Noncentral Potentials 659

20.5.1 Introduction $\quad 659$

20.5.2 The Generalized Marchenko Equation 659

20.5.3 A Generalized Gel'fand-Levitan Equation . 665

20.5.4 Potential Obtained from Backscattering 666

Notes and References $\quad 667$

$\begin{array}{lr}\text { Problems } & 670\end{array}$

$\begin{array}{ll}\text { Bibliography } & 671\end{array}$

$\begin{array}{lll}\text { Index } & 727\end{array}$

$\begin{array}{ll}\text { Errata } & 745\end{array}$ 